\title{
Preparing for a COVID-19 pandemic: a review of outbreak response measures from Australia perspective
}

\author{
Rama Jayaraj, ${ }^{1,2}$, Chellan Kumarasamy ${ }^{3}$, Ravishankar Ram M4, Gothandam KM ${ }^{5}$, Devi $\mathrm{A}^{6}$ and Peter Shaw ${ }^{2,7}$ \\ ${ }^{1}$ Northern Territory Institute of Research and Technology, Darwin, Australia \\ ${ }^{2}$ Department of Artificial Intelligence, Nanjing University of Information Science and Technology (NUIST), Jiangsu, China \\ ${ }^{3}$ School of Public Health, The University of Adelaide, North Terrace Campus, Adelaide, SA, 5005, Australia \\ ${ }^{4}$ Department of Genetics and Molecular Biology Institute of Biological Sciences, Faculty of Science, University of Malaya, 50603 Kuala Lumpur, Malaysia \\ ${ }^{5}$ School of Biosciences and Technology, Vellore Institute of Technology (VIT), Vellore, Tamil Nadu, India \\ ${ }^{6}$ Cancer Research and Stem Cell Biology, Department of Genetic Engineering, Kattankulathur Campus, SRM Institute of Science and Technology, India \\ ${ }^{7}$ Menzies School of Health Research, Darwin, Australia
}

As the understanding of the viral pyramid evolves, its transformation from the animal host to the human host and the pattern of transmission needs to be explored. An immunocompromised host enables viral replication, with lethal outcome. An in-depth insight into COVID 19's epidemiology, inoculation into the host, the spillover from animals to humans pirating the genetic machinery and advantageous mutations is essential. Albeit many features observed in the virus spread are in contrast to the common viral infections, the geographical variance such as, how the virus acclimatises to the cold conditions in the western part of the world (where its spread has been widespread), compared to viral spread in hot and humid conditions found in the eastern parts of the world is yet to be decoded. The mutable spectrum of these miniature organisms ranging from severe SARS (severe acute respiratory syndrome), MERS (Middle East respiratory syndrome), avian influenza $\mathrm{A}(\mathrm{H} 7 \mathrm{~N} 9)$, and influenza $\mathrm{A}(\mathrm{H} 1 \mathrm{~N} 1)$ pdm09 explains its dynamic evolvement and an urge to inoculate into humans. Critical care will be an integral component to tackle these lethal viruses. Countries such as Australia for instance where the virus is yet to leap into Stage 3 (community transmission) as compared to other countries in the Western world must act swiftly to maintain an equilibrium of safety for patients as well as the community [1]. We discuss how the outbreak response measures can be managed by adopting a " $6 \mathrm{~T}$ " framework that would help to plan the necessary measures during each phase of a pandemic. These measures are crucial to augment the quality of health care provided to COVID-19 patients to reduce the risk of viral transmission and cripple the health care system.

\section{Global pandemic and renaissance of the healthcare system}

Coronaviruses are a large group of RNA viruses, which contain a core of genetic material surrounded by an envelope of protein spikes [2], giving it an appearance of a crown (the etymology of the name 'coronavirus'). The spillover of COVID19 from animals to humans and its transformation is yet to be understood. The genetic fingerprint of the virus is ascertained in vitro by the Polymerase Chain Reaction (PCR) while its resiliency and invisible ubiquitous viability in the environment has enabled the chain of transmission to progress rapidly within a population. The infectivity of the virus is impelled by an extended incubation period (5-7 days) of asymptomatic shedding resulting in an outsized number of carriers [3].
The outbreak of novel COVID 19 in China has resulted in a global pandemic, being announced by the World Health Organisation in February 2020. Apart from the highly infectious nature of the virus contributing to elevated transmission rate, the lacklustre response of healthcare systems worldwide indicate there seems to be an urgent need for a renaissance of the global healthcare system. The race between life and death, enveloped by medical, economic and psychological concerns caused by the virus has led to a myriad of fallacies in handling the virus. The poor prognosis of COVID 19 patients is often associated with key risk factors including sex, age, underlying comorbidities and secondary acute respiratory distress syndrome. The synergy of clinical expertise and computer modelling may help in curtailing the spread of this highly evolved disease.

\section{A concoction of drugs and substitution}

Convalescent plasma and H-Ig can offer passive antibodies, that in turn can lead to herd immunity [4]. The plasma in patients who have relapse despite treatment may have a high viral load and a surge of antibodies , this needs to be thoroughly evaluated.

There has been growing evidence suggesting that opioids may play a role in amplifying the replication of human immunodeficiency virus and hepatitis $C$ virus in target cells [5]. In the same vein, it is hypothesized that low dose analgesics which have a divergent pain release mechanism, similar to that of opioids may subdue the cytokine storm observed in COVID 19 [6,7].

\section{Current medical research approaches}

The medical research field in Australia, as well as around the globe, is working hard and fast to analyse, assess and develop any viable treatment methods and strategies against COVID 19. Many new studies are being published every day, with a number of them discussing

${ }^{*}$ Correspondence to: Rama Jayaraj, PhD., MPH. (RJ), Northern Territory Institute of Research and Technology, Darwin, Australia and Department of Artificial Intelligence, Nanjing University of Information Science and Technology (NUIST), Jiangsu, China, E-mail: jramamoorthi@gmail.com

Received: April 13, 2020; Accepted: May 08, 2020; Published: May 12, 2020 
clinical methods of ameliorating COVID 19's spread. A study assessing Lianhuaqingwen (LH) a traditional Chinese medicine used to treat influenza has discovered that LH inhibited SARS-CoV-2 replication and reduced cytokine levels [8]. Another study conducted, recognized that hydroxychloroquine, alongside azithromycin led to an effective reduction of viral load in COVID19 patients [9]. A common theme among these treatment strategies is the effort to identify previously existing methods of treatments, proven to be useful in diseases of similar pathophysiology, which may be capable of use in treating/ handling COVID19. This precedent is further reflected in efforts, such as that of Australia, where health workers are being trailed with a TB vaccine, to see whether it has protective effects against COVID19 as well (2020a) [10]. Clinicians are also attempting to put forward novel treatment strategies for COVID19, for expedited approval by their respective governments, such as the "cytokine concoction" strategy for re-triggering the immune system in SARS-Cov-2 infection, which has been presented by an oncologist in India (2020b) [11].

Another subset of studies that help contextualise the current global health crisis that we face are epidemiological studies such as the Wuhan study assessing the clinical course and risk factors for mortality of adult inpatients with COVID19, which have helped glean crucial knowledge regarding the effects, risks and hazards of the disease, allowing the healthcare systems of the world to better assess and combat the disease at the population level [12].

\section{Outbreak response measures for the prevention}

The emergence of new clusters of disease and corresponding waves of infection has lead to Australian Government adopting "lock-downs" and "self-isolation" of entire countries due to a failure in comprehending the seriousness of global threat resulting in a delay (or failure) to adopt stringent measures rapidly. The clusters need to be predicted, detected and quarantined if the disease is to be curtailed.

The outbreak response steps are based on the " $6 \mathrm{~T}$ " principle:

\section{Trace the contacts}

2. Terminate COVID 19 transmission: breaking its chain by social distancing

3. Test the suspects

4. Treat the positive patients and quarantine the rest if in doubt

5. Transforming the host by triggering the immune response and prevent the integration of the virus.

6. Take proactive steps: Hand hygiene, Deep breathing exercises (Eupnoea), Face mask. Do not touch face, nose and mouth with unclean hands.

The following steps can/are being taken as approaches to address the rapid transmission and progression of the SarsCov2 virus in population as well as for the treatment for affected individuals;

- Restricting the locomotion of individuals within high-risk zones,

- Quarantining of individuals suspected to have infection could be marked by a temporary stamp/seal/identification bracelet in a conspicuous part of the body, for easier identification.

- Home quarantined individuals should have a real-time tracking/ GPS, awareness system regarding the innocuous route of viral spread, administered through an IT framework created by the government.
- Rejuvenation of affected individuals who are often in a state of denial, by psychologists and psychiatric social workers with telephonic counselling and support. This may also prevent attempts of deliberate escape by individuals from hospital wards due to the frustration of being isolated (emotional distancing).

- Alcohol withdrawl during a total lockdown needs to be considered.

- Development of an algorithm to trace the whereabouts of the suspected patients (contact tracing) and active surveillance of high-risk localities using drones and members of the allied health specialities.

- Reinforcement of the Primary health care centres (The first level of contact for an average population)

- Scaling down of religious gatherings, live-streaming as an alternative for important events, and promoting telecommunication of face-toface meetings are few of the practical life adjustments that can halt sustained community transmission.

- Decongesting hospitals by deferring elective medical and surgical procedures (eg dental procedures generating aerosols, cosmetic surgeries) and routine health check-ups, along with reinforcing a strict referral system and minimising bystanders.

- Rebooting of the immune system by cyclic meditation ${ }^{6,78} .1 \mathrm{cc}$ of blood harbours in an immunocompetent individual on an average consists of 4000-11000 leucocytes capable enough to take a toll on the virus. The current lockdown and social distancing in several parts of the world may douse the viral wildfire, but a deep understanding on the innate immune response against the virus may outweigh the current ambiguous symptomatic treatment against the viral replication.

- An official Australian COVID 19 app and WhatsApp number from the Department of Health (24x7 Helpline): to have a single consolidated source of communication and information to quell myths, fake claims of cure and promote safety guidelines and awareness This can impact the social and psychological resilience of individuals as they tide over this biological war that extends before us.

\section{Conclusions}

Preparation for a pandemic comprises the different levels in the hierarchy of controls as well as the different phases of the pandemic. As the virus promulgates throughout the globe creating an unprecedented crisis there is a need to revamp the health care system, revision of government ordinance and injecting financial liquidity to the needy.

\section{References}

1. Ma Y, Zhao Y, Liu J, He X, Wang B, et al. (2020) Effects of temperature variation and humidity on the mortality of COVID-19 in Wuhan. medRxiv.

2. Bárcena M, Oostergetel GT, Bartelink W, Faas FGA, Verkleij A, et al. (2009) Cryoelectron tomography of mouse hepatitis virus: Insights into the structure of the coronavirion. Proc Natl Acad Sci U S A 106: 582-587. [Crossref ]

3. Lai CC, Liu YH, Wang CY, Wang YH, Hsueh SC, et al. (2020) Asymptomatic carrier state, acute respiratory disease, and pneumonia due to severe acute respiratory syndrome coronavirus 2 (SARSCoV-2): Facts and myths. J Microbiol Immunol Infect. [Crossref ]

4. Roback JD, Guarner J (2020) Convalescent Plasma to Treat COVID-19: Possibilities and Challenges. JAMA. [Crossref ]

5. Chen YH, Wu KL, Tsai MT, Chien WH, Chen ML, et al. (2017) Methadone enhances human influenza A virus replication. Addict Biol 22: 257-271. [Crossref ] 
6. Amici C, La Frazia S, Brunelli C, Balsamo M, Angelini M, et al. (2015) Inhibition of viral protein translation by indomethacin in vesicular stomatitis virus infection: role of eIF2alpha kinase PKR. Cell Microbiol 17: 1391-1404. [Crossref ]

7. Burki TK (2020) Coronavirus in China. Lancet Respir Med 8: 238. [Crossref]

8. Runfeng L, Yunlong H, Jicheng H, Weiqi P, Qinhai M, et al. (2020) Lianhuaqingwen exerts anti-viral and anti-inflammatory activity against novel coronavirus (SARSCoV-2). Pharmacol Res.

9. Gautret P, Lagier JC, Parola P, Hoang VT, Meddeb L, et al. (2020) Hydroxychloroquine and azithromycin as a treatment of COVID-19: results of an open-label non-randomized clinical trial. Int J Antimicrob Agents. [Crossref ]
10. Australia's trialing a TB vaccine against COVID-19, and health workers get it first [Internet]. Science Alert. Available from: https://www.sciencealert.com/australia-istrialling-a-tb-vaccine-for-coronavirus-and-health-workers-get-it-first.

11. Bengaluru oncologist claims to be close to discovering cure for coronavirus [Internet] The Economic Times. Available from: https://economictimes.indiatimes.com/news/ politics-and-nation/bengaluru-oncologist-claims-to-be-close-to-discovering-cure-forcoronavirus/videoshow/74853699.cms.

12. Zhou F, Yu T, Du R, Fan G, Liu Y, et al. (2020) Clinical course and risk factors for mortality of adult inpatients with COVID-19 in Wuhan, China: A retrospective cohort study. Lancet 395: 1054-1062. [Crossref ]

Copyright: (C2020 Jayaraj R. This is an open-access article distributed under the terms of the Creative Commons Attribution License, which permits unrestricted use, distribution, and reproduction in any medium, provided the original author and source are credited. 